\title{
CONTACT SHELL APPLICATOR FOR USE AS A CORNEAL BATH*
}

\author{
BY \\ M. KLEIN \\ LONDON
}

INSTILLED eyedrops disappear from the conjunctival sac within a few minutes (Ridley, 1931/32) and if it is desired that the drug should act for a long time, one has to use it in ointment-form (preferably under bandage) or as a corneal bath. Contact shells are also useful for the local application of drugs to the eye (Klein, 1942), and have proved satisfactory during the past eight years.

The contact applicator looks like a rather heavy contact-lens with two studs on the corneal portion. The scleral part has a diameter

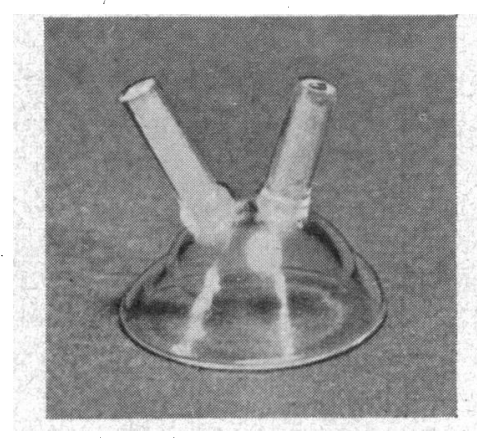

FIG. 1.

of $20 \mathrm{~mm}$. and a scleral radius of curvature of $12 \mathrm{~mm}$. The corneal segment is raised so as to form a chamber for the fluid. The two small studs serve as a handle when inserting the applicator under the lids, and each of them has a bore reaching into the chamber, one for filling up the chamber by means of an eye-dropper, and the other for the escape of air. One drop of half per cent. 'amethocaine hydrochloride gives sufficient anaesthesia.

To insert the contact applicator the patient is asked to look down, and the upper margin of the contact applicator is slipped under the upper lid. The patient is then told to look up, and the applicator is placed on the eye under the lower lid. Then it is filled up with the solution used for treatment, and the applicator is left in position for the desired period, usually 5 to 30 minutes. If necessary it can

- Received for publication, April 11, 1949. 
be refilled. It can be cleaned by washing with soap and water, and chemically sterilized by keeping it in 1:1000 mercuric bichloride or in chlorine solution (Solvellae Chloramine B.P.C: in $4 \mathrm{oz}$. water) for $15-20$ minutes, followed by rinsing. Alcoholic solutions, phenolic antiseptics or heat sterilization are not suitable, as they are detrimental to the plastic material of which the applicator is made.

The contact applicator can be used for any solutions such as sulphonamides, mydriatics, miotics, urea, etc. Struble and Bellow's (1944 and 1946) have shown that a high concentration of penicillin in the anterior segment of the eye can be built up by the use of a corneal bath, and they have advocated this procedure for the treatment of corneal ulcers, particularly if the deeper layers are involved. In chemical burns the applicator can be used for continuous irrigation with the antidote, such as ammonium tartarate solution in lime-burns. For irrigation a suitably placed flask or undine can be connected with rubber tubing.

The contact applicator is manufactured by Messis. G. Nissel and Co. Ltd., Siddons Lane, London, N. W.1.

\section{REFERENCES}

Ridley, F. T. (1931)-Proc. Roy. Soc. Med., 25, 480.

KLEIN, M. (1942)-Trans. Ophth. Soc. U.K., 62, 43.

Struble, G. C. \& Bellows, J. G. (1944)-J.A.M.A., 125, 485.

Struble, G. C. \& Bellows, J. G. (1946)-Arch. Ophth., 35, 173.

\section{FACULTY TOUR OF ITALIAN CLINICS}

UNDER arrangements made by the Faculty of Ophthalmologists, twenty members, led by Dr. Robert Buxton, were able to make a tour of 'centres of ophthalmology in Italy, the clinics visited being those at Pavia, Genoa, Florence, Rome, Naples and Bologna. At each of these places the hospitality of the professors, and the opportunities for seeing the beauties of their cities, contributed greatly to the enjoyment of what was, in any case, an interesting and instructive tour.

At Pavia the party was welcomed by Professor Bietti and taken to a reception given by the Rector of the University of Pavia. In one of the courtyards of the University is a statue of Scarpa, the first Professor of Ophthalmology of Pavia.

At the Ophthalmic Clinic next morning Professor Bietti showed a number of cases on which keratoplasty had been performed, and demonstrated his technique. He also gave a lecture on Chemotherapy in Tuberculosis. He advised early administration of streptomycin $(0.5 \mathrm{gm}$. b.d. subcutaneously) which may be given with 